\title{
INTENSITY OF DENTAL CARIES IN TEENAGERS TREATED WITH FIXED APPLIANCES
}

\author{
Urszula Kozak \\ Chair and Department of Jaw Orthopedics, Medical University of Lublin, Poland
}

\begin{abstract}
INTRODUCTION: The goal of orthodontic treatment is the improvement of oral health. Unfortunately, orthodontic therapy carries a risk of complications. Most frequent reported problem is dental caries.

ОвJеCTIVEs: The aim of this work was an assessment of intensity of dental caries and dental treatment index in young patients treated with fixed appliances.

MATERIAL AND MeTHODs: Study included 144 patients, aged 12-18 years. The patients were divided into 2 groups, including one group with orthodontic treatment and one control group. The study was conducted in 3 stages, such as before orthodontic treatment, after a month, and after 6 months of therapy. Decayed, missing, and filled teeth (DMFT) value and caries treatment index were assessed.

RESults: Distribution of DMFT values in the first, second, and third stages of the study was not statistically different $(p>0.05)$ in the group with orthodontic treatment and control group. However, statistically significant difference was found in the assessment of DMFT changes in the group having orthodontic treatment during halfyear observation period. The DT value was observed to decrease (from 0.67 to 0.33 ), while FT value increased significantly (from 3.68 to 4.15 ) during each of the three stages of the study.

ConcLusions: Orthodontic treatment does not significantly influence an increase of DMFT index in the patients with orthodontic treatment compared to patients without orthodontic therapy. Frequent visits at the dentist's office during an orthodontic treatment resulted in an increase of caries treatment index in orthodontic patients.
\end{abstract}

KEY wORDS: adolescent, dental caries, fixed orthodontic appliances.

J Stoma 2020; 73, 5: 254-260

DOI: https://doi.org/10.5114/jos.2020.100542

\section{INTRODUCTION}

Orthodontic therapy provides a change in the environment of oral cavity, with a risk of complications. The most frequent problem reported by orthodontists is dental caries [1]. The studies carried out so far indicate that fixed braces may additionally influence initiating or intensification of cariogenic process as they limit the flow of saliva, which naturally cleans the teeth and creates a retentive surface, where bacterial species are able to reproduce and where there is an increased diffi- culty in maintaining oral hygiene. The grade of bacterial colonization related to orthodontic appliances is affected by the energy and roughness of appliances surfaces as well as their design and dimensions [2]. Moreover, the excess of cement around orthodontic brackets additionally fosters bacteria proliferation. While complete removal of excess adhesive around the bracket is desirable, it can be sensitive and time-consuming task [3]. Orthodontic appliances break the salivary homeostasis of microorganisms involved in dental caries [4]. After placing fixed braces, some changes in dental plaque were

\section{JOURNAL OF} STOMATOLOGY CZASOPISMO STOMATOLOGICZNE

AdDress For CORRESPONDENCE: Dr. Urszula Kozak, Chair and Department of Jaw Orthopedics, Medical University of Lublin, 6 Dra W. Chodźki St., 20-093 Lublin, Poland, e-mail: urszulakozak@umlub.pl 
observed, including an increase in the number of Streptococcus mutans, Lactobacillus bacteria, and carbohydrates as well as lower resting plaque's $\mathrm{pH}[5,6]$. Therefore, caries prevention from the beginning of therapy is necessary. Careful hygienic procedures are needed to reduce the risk of dental caries after orthodontic treatment [7]. With poor oral hygiene, which impacts the appearance of caries or periodontal lesions in patients during active treatment, it is recommended to complete or postpone the therapy in order to avoid further iatrogenic lesions as well as to conduct an effective treatment.

\section{OBJECTIVES}

The aim of this work was an assessment of intensity of dental caries and dental treatment index in young patients treated with fixed appliances.

\section{MATERIAL AND METHODS}

In total, the present study involved 144 patients aged 12-18 years, with 94 girls and 50 boys. The participants were divided into 2 groups: orthodontically treated and control. The group of patients treated orthodontically included patients qualified for treatment with conventional fixed orthodontic braces. The control group consisted of students attending schools located in the Lublin province, Poland. In each of the schools, there were dental offices. The mean age of patients in orthodontically treated group was 14.03 and in control group, it was 13.48.

A total of 60 patients undergoing treatment with fixed appliances (42 girls and 18 boys) and 84 control students attending schools in Lubelskie voivodship (52 girls and 32 boys) were examined.

Clinical examination of patients from the group with orthodontic treatment was conducted at the Chair and Department of Jaw Orthopedics of the Medical University of Lublin. The control group, without orthodontic treatment, was examined in school dental offices.

The research was approved by bioethics committee, patients, parents/caregivers, schools' principals, and schools' dentists.

Generally healthy patients were qualified to the study group. Due to the fact that a formation of carious lesion takes at least 6 months, the observation period included first half of the year of treatment with fixed braces.

The study excluded persons who had been previously covered with orthodontic therapy, patients after gnathic treatment, and patients who presented with lesions in enamel of non-cariogenic origin. Adequately to the study group, the control group was formed. In both groups, the assessment of intensity of dental caries was divided into three stages:

- stage 1: preliminary examination of patients qualified for orthodontic treatment was carried out during a visit prior the insertion of permanent appliance;
- stage 2: 1 month after the placement of the braces;

- stage 3: 6 months after the treatment.

Measurements in the orthodontically treated and control group patients were completed by the same examiner.

The physical examination was carried out in a dental office using a shadeless lamp, with a flat mirror and periodontal probe WHO-621. Clinical examination included an assessment of DMFT index and caries treatment index. DMFT value means the total number of teeth with active caries either primary or secondary, teeth extracted due to caries, and restored teeth.

$\mathrm{DMFT}=\mathrm{D}+\mathrm{M}+\mathrm{F}$,

where DT means decayed permanent teeth with primary caries, with one or several cavities and/or secondary caries (tooth with temporary filling is treated as decayed tooth), MT means missing permanent teeth due to caries, and FT means permanent teeth with one or more restorations, without secondary caries, teeth with a crown due to previous decay.

DMFT value higher than 0 indicates that a person has or had caries. Dental treatment index is the ratio of number of filled teeth to the total number of teeth with caries and filled teeth.

$$
\text { Treatment index }=\frac{F}{D+F},
$$

where $F$ is the number of teeth with fillings without secondary caries, and $D$ is the number of teeth with caries or fillings with secondary caries.

An assessment of caries treatment index suggests dental care in a population, effectiveness of routine preventive methods, and systematic control visits. It allows for the evaluation of existing effectiveness of care and therapeutic actions, comparison, prediction, and planning. The values of this index ranged between 0 and 1 . Values from 0 to 0.5 indicated absence or low effectiveness of treatment, while values over 0.5 or close to 1 showed higher/high effectiveness.

\section{STATISTICAL ANALYSIS}

The results of clinical examinations were statistically analyzed using Statistica v.8.0 (StatSoft Polska, Poland).

\section{RESULTS}

\section{DMFT VALUES AND ITS COMPONENTS}

On the basis of Mann-Whitney $U$ test, it can be concluded that distribution of DMFT index in the first, second, and third examination in the group with orthodontic treatment and control group was not statistically 
TABLE 1. Average DMFT index and its components in both analyzed groups

\begin{tabular}{|c|c|c|c|c|c|c|c|c|c|c|}
\hline Group & DMFT & $n$ & M & SD & V & Min & Max & Q1 & Me & Q3 \\
\hline \multirow[t]{3}{*}{ With orthodontic treatment } & DMFT1 & 60 & 4.35 & 3.00 & $69.0 \%$ & 0.00 & 15.00 & 2.00 & 4.00 & 6.50 \\
\hline & DMFT 2 & 60 & 4.35 & 3.00 & $69.0 \%$ & 0.00 & 15.00 & 2.00 & 4.00 & 6.50 \\
\hline & DMFT 3 & 60 & 4.48 & 3.05 & $68.0 \%$ & 0.00 & 15.00 & 2.00 & 4.00 & 7.00 \\
\hline \multirow[t]{3}{*}{ Control } & DMFT 1 & 84 & 4.10 & 3.00 & $73.3 \%$ & 0.00 & 14.00 & 2.00 & 4.00 & 6.00 \\
\hline & DMFT 2 & 84 & 4.10 & 3.00 & $73.3 \%$ & 0.00 & 14.00 & 2.00 & 4.00 & 6.00 \\
\hline & DMFT 3 & 84 & 4.15 & 3.05 & $73.4 \%$ & 0.00 & 14.00 & 2.00 & 4.00 & 6.00 \\
\hline \multirow[t]{3}{*}{ With orthodontic treatment } & D1 & 60 & 0.67 & 1.26 & $188.7 \%$ & 0.00 & 6.00 & 0.00 & 0.00 & 1.00 \\
\hline & D2 & 60 & 0.52 & 1.14 & $221.1 \%$ & 0.00 & 6.00 & 0.00 & 0.00 & 1.00 \\
\hline & D3 & 60 & 0.33 & 0.82 & $244.9 \%$ & 0.00 & 4.00 & 0.00 & 0.00 & 0.00 \\
\hline \multirow[t]{3}{*}{ Control } & D1 & 84 & 0.90 & 1.39 & $153.1 \%$ & 0.00 & 7.00 & 0.00 & 0.00 & 1.50 \\
\hline & D2 & 84 & 0.86 & 1.38 & $161.1 \%$ & 0.00 & 7.00 & 0.00 & 0.00 & 1.00 \\
\hline & D3 & 84 & 0.81 & 1.38 & $169.9 \%$ & 0.00 & 7.00 & 0.00 & 0.00 & 1.00 \\
\hline \multirow[t]{3}{*}{ With orthodontic treatment } & M1 & 60 & 0.00 & 0.00 & - & 0.00 & 0.00 & 0.00 & 0.00 & 0.00 \\
\hline & M2 & 60 & 0.00 & 0.00 & - & 0.00 & 0.00 & 0.00 & 0.00 & 0.00 \\
\hline & M3 & 60 & 0.00 & 0.00 & - & 0.00 & 0.00 & 0.00 & 0.00 & 0.00 \\
\hline \multirow[t]{3}{*}{ Control } & M1 & 84 & 0.01 & 0.11 & $916.5 \%$ & 0.00 & 1.00 & 0.00 & 0.00 & 0.00 \\
\hline & M2 & 84 & 0.01 & 0.11 & $916.5 \%$ & 0.00 & 1.00 & 0.00 & 0.00 & 0.00 \\
\hline & M3 & 84 & 0.01 & 0.11 & $916.5 \%$ & 0.00 & 1.00 & 0.00 & 0.00 & 0.00 \\
\hline \multirow[t]{3}{*}{ With orthodontic treatment } & F1 & 60 & 3.68 & 2.80 & $75.9 \%$ & 0.00 & 15.00 & 2.00 & 3.00 & 5.00 \\
\hline & F2 & 60 & 3.83 & 2.87 & $74.9 \%$ & 0.00 & 15.00 & 2.00 & 4.00 & 5.00 \\
\hline & F3 & 60 & 4.15 & 2.90 & $69.8 \%$ & 0.00 & 15.00 & 2.00 & 4.00 & 6.00 \\
\hline \multirow[t]{3}{*}{ Control } & F1 & 84 & 3.18 & 2.68 & $84.2 \%$ & 0.00 & 12.00 & 1.00 & 3.00 & 5.00 \\
\hline & $\mathrm{F} 2$ & 84 & 3.23 & 2.66 & $82.6 \%$ & 0.00 & 12.00 & 1.00 & 3.00 & 5.00 \\
\hline & F3 & 84 & 3.33 & 2.71 & $81.2 \%$ & 0.00 & 12.00 & 1.50 & 3.00 & 5.00 \\
\hline
\end{tabular}

TABLE 2. Mann-Whitney $U$ test values for DMFT and its components

\begin{tabular}{|c|c|c|c|c|}
\hline Comparison & DMFT & $\boldsymbol{U}$ & $Z$ & $p$-value \\
\hline \multirow[t]{3}{*}{ Group with orthodontic treatment and control group } & DMFT1 & 2365.5 & 0.6280 & 0.5300 \\
\hline & DMFT 2 & 2365.5 & 0.6280 & 0.5300 \\
\hline & DMFT 3 & 2325.0 & 0.7929 & 0.4278 \\
\hline \multirow[t]{3}{*}{ Group with orthodontic treatment and control group } & D1 & 2212.5 & -1.4225 & 0.1549 \\
\hline & D2 & 2114.0 & -1.9310 & 0.0535 \\
\hline & D3 & 2007.5 & -2.5366 & 0.0112 \\
\hline \multirow[t]{3}{*}{ Group with orthodontic treatment and control group } & M1 & 2490.0 & -0.8311 & 0.4059 \\
\hline & M2 & 2490.0 & -0.8311 & 0.4059 \\
\hline & M3 & 2490.0 & -0.8311 & 0.4059 \\
\hline \multirow[t]{3}{*}{ Group with orthodontic treatment and control group } & F1 & 2224.5 & 1.2058 & 0.2279 \\
\hline & F2 & 2180.5 & 1.3851 & 0.1660 \\
\hline & F3 & 2071.0 & 1.8334 & 0.0668 \\
\hline
\end{tabular}

different $(p>0.05)$. ANOVA Friedman test showed that in the group with orthodontic treatment, DMFT index assessments in the first, second, and third examination were statistically different $(p<0.05)$. Wilcoxon signed- rank test revealed that DMFT values in the first and third examinations as well as in the second and third examinations in the group with orthodontic treatment were statistically different $(p<0.05)$. Due to the lack 
TABLE 3. ANOVA Friedman test and Wilcoxon signed-rank test values for DMFT and its components

\begin{tabular}{|c|c|c|c|c|c|}
\hline Group & $\begin{array}{c}\text { ANOVA } \\
\text { Friedman test }\end{array}$ & $p$-value & Comparison & $\begin{array}{c}\text { Z test } \\
\text { Wilcoxon signed-rank }\end{array}$ & $p$-value \\
\hline \multirow[t]{3}{*}{ With orthodontic treatment } & \multirow[t]{3}{*}{12.00} & \multirow[t]{3}{*}{0.0025} & DMFT1 and DMFT2 & - & - \\
\hline & & & DMFT1 and DMFT3 & 2.20 & 0.0277 \\
\hline & & & DMFT2 and DMFT3 & 2.20 & 0.0277 \\
\hline \multirow[t]{3}{*}{ Control } & \multirow[t]{3}{*}{5.56} & \multirow[t]{3}{*}{0.0622} & DMFT1 and DMFT2 & - & - \\
\hline & & & DMFT1 and DMFT3 & 1.48 & 0.1386 \\
\hline & & & DMFT2 and DMFT3 & 1.48 & 0.1386 \\
\hline \multirow[t]{3}{*}{ With orthodontic treatment } & \multirow[t]{3}{*}{12.47} & \multirow[t]{3}{*}{0.0020} & D1 and D2 & 2.52 & 0.0117 \\
\hline & & & D1 and D3 & 2.41 & 0.0158 \\
\hline & & & D2 and D3 & 1.64 & 0.1005 \\
\hline \multirow[t]{3}{*}{ Control } & \multirow[t]{3}{*}{4.90} & \multirow[t]{3}{*}{0.0863} & D1 and D2 & 1.60 & 0.1088 \\
\hline & & & D1 and D3 & 1.27 & 0.2043 \\
\hline & & & D2 and D3 & 0.69 & 0.4925 \\
\hline \multirow[t]{3}{*}{ With orthodontic treatment } & \multirow[t]{3}{*}{-} & \multirow[t]{3}{*}{-} & $\mathrm{M} 1$ and $\mathrm{M} 2$ & - & - \\
\hline & & & M1 and M3 & - & - \\
\hline & & & $\mathrm{M} 2$ and $\mathrm{M} 3$ & - & - \\
\hline \multirow[t]{3}{*}{ Control } & \multirow[t]{3}{*}{-} & \multirow[t]{3}{*}{-} & $M 1$ and $M 2$ & - & - \\
\hline & & & $M 1$ and $M 3$ & - & - \\
\hline & & & $M 2$ and $M 3$ & - & - \\
\hline \multirow[t]{3}{*}{ With orthodontic treatment } & \multirow[t]{3}{*}{23.72} & \multirow[t]{3}{*}{$<0.0001$} & $\mathrm{~F} 1$ and F2 & 2.52 & 0.0117 \\
\hline & & & $\mathrm{F} 1$ and F3 & 3.48 & 0.0005 \\
\hline & & & $\mathrm{F} 2$ and $\mathrm{F} 3$ & 2.95 & 0.0032 \\
\hline \multirow[t]{3}{*}{ Control } & \multirow[t]{3}{*}{10.78} & \multirow[t]{3}{*}{0.0046} & $\mathrm{~F} 1$ and F2 & 1.60 & 0.1088 \\
\hline & & & $\mathrm{F} 1$ and F3 & 2.49 & 0.0129 \\
\hline & & & $F 2$ and F3 & 1.86 & 0.0627 \\
\hline
\end{tabular}

of differentiation of the results, it was impossible to use Wilcoxon signed-rank test to compare DMFT index in the first and second examinations.

On the basis of ANOVA Friedman test, it can be said that in the control group the DMFT values assessed in the first, the second and the third examination were not statistically different $(p>0.05)$, therefore were not changing over time. Moreover, on the basis of Wilcoxon signed-rank test, it can be concluded that DMFT index in the first and the third examination, as well as in the second and the third examination in the control group were not statistically different $(p>0.05)$. Due to the lack of differentiation of results, it was impossible to use Wilcoxon signed-rank test to compare DMFT values in the first and in the second examination.

On the basis of values of descriptive statistics, it can be concluded that in the group with orthodontic treatment,
DMFT index was lower before fixed braces application compared to values obtained after 6 months of therapy. The values obtained after a month of treatment with fixed braces were also lower compared to data obtained after 6 months of treatment. Mann-Whitney $U$ test revealed that distribution of decayed teeth in the first and second examinations in the group with orthodontic treatment and in control group was not statistically different $(p>0.05)$. While distribution of decayed teeth obtained in the third examination in the group with orthodontic treatment and in control group was statistically different $(p<0.05)$.

On the basis of values of some descriptive statistics, it can be concluded that the number of decayed teeth obtained after six-month observation period was lower in the group with orthodontic treatment than in control group.

ANOVA Friedman test indicated that in the group with orthodontic treatment, the number of decayed teeth 
TABLE 4. Dental treatment index values in both analyzed groups

\begin{tabular}{|c|c|c|c|c|c|c|}
\hline \multirow[t]{2}{*}{ Treatment index } & \multicolumn{3}{|c|}{ Group with orthodontic treatment } & \multicolumn{3}{|c|}{ Control group } \\
\hline & DTI1 & DTI2 & DTI3 & DTI1 & DT12 & DTI3 \\
\hline Girls & 0.86 & 0.89 & 0.95 & 0.77 & 0.78 & 0.8 \\
\hline Boys & 0.83 & 0.88 & 0.86 & 0.81 & 0.81 & 0.81 \\
\hline Girls + boys & 0.85 & 0.89 & 0.93 & 0.78 & 0.79 & 0.8 \\
\hline
\end{tabular}

in the first, second, and third examinations was statistically different $(p<0.05)$. On the basis of Wilcoxon signed-rank test, $D$ values in the first and second as well as in the first and third examinations in the studied groups were statistically different $(p<0.05)$. Although, $D$ values in the second and third examinations in the group with orthodontic treatment were not statistically different $(p>0.05)$. Moreover, based on ANOVA Friedman test, in the control group, the number of decayed teeth in the first, second, and third examination was not statistically different $(p>0.05)$; therefore, no change over time was observed. On the basis of Wilcoxon signed-rank test, it can be concluded that $D$ values in the first and second, the first and third as well as in the second and third examinations in the control group were not statistically different $(p>0.05)$.

On the basis of values of certain descriptive statistics, it can be concluded that in the group with orthodontic treatment, the number of decayed teeth was higher before fixed braces placement than a month and 6 months after the placement of braces. In the group with orthodontic treatment, no extracted tooth due to caries was recorded $(M=0)$.

Based on Mann-Whitney $U$ test, it can be concluded that distribution of $M$ values in the first, second, and third examinations in both the group with orthodontic treatment and control group were not statistically different $(p>0.05)$. Due to the lack of differentiation in the number of missing teeth at different stages of examination in both the group with orthodontic treatment and control group, it was impossible to use non-parametric ANOVA Friedman test and non-parametric Wilcoxon signed-rank test. Based on Mann-Whitney $U$ test, it can be concluded that distribution of $F$ values in the first, the second and the third examination in the group with orthodontic treatment and control group were not statistically different $(p>0.05)$. On the basis of ANOVA Friedman test, in both the group with orthodontic treatment and control group, the number of restored teeth in the first, second, and third examinations was statistically different $(p<0.05)$. Moreover, on the basis of Wilcoxon signed-rank test, it can be concluded that the number of restored teeth in the first and second, the first and third as well as in the second and third examinations, in the group with orthodontic treatment was statistically different $(p<0.05)$. Also, the comparison of $F$ values in the first and third examinations in the control group showed statistical difference $(p<0.05)$. Furthermore, the number of restored teeth in the first and second as well as in the second and third examinations in the control group was not statistically different $(p>0.05)$. Concerning the values of certain descriptive statistics, in the group with orthodontic treatment, the lowest $F$ values were obtained before the beginning of orthodontic therapy and slightly higher values were recorded a month after placing fixed braces, while the highest number of restored teeth was observed after 6 months of treatment with fixed braces. In the control group, $F$ values in the first examination were lower than values assessed after 6 months.

\section{DENTAL TREATMENT INDEX}

In the present study, good effectiveness of treatment caries in both analyzed groups was observed (Table 4). However, the comparison of treatment index values in both the group with orthodontic treatment and control group showed quite better effectiveness of conducted therapeutic procedures in the group with orthodontic treatment (increase of index value from 0.85 in the first examination to 0.93 in the third one) compared to the control group ( 0.78 in the first examination and 0.8 after the six-month observation period).

\section{DISCUSSION}

In the last three decades, the level of tooth decay in Poland has been reduced by half, but it is still 3 times higher than in other European countries [8]. The values of caries intensity among teenagers in Poland are still high [9]. Untreated dental-maxillo-facial defects predispose to the appearance of teeth caries. Unfortunately, during an orthodontic treatment, there is a danger of development of carious lesions, because oral cavity creates environment, which is suitable for numerous microorganisms and fixed braces interferes with natural ontocenosis of oral cavity. Moreover, auxiliary wire elements create surfaces that are impossible to clean in home setting. During a treatment with fixed braces, there is a risk of development of caries lesions under loose or incorrectly cemented rings.

The results of the present study showed that during the whole observation period, DMFT value in the group of teenagers with orthodontic treatment was higher than 
in the control group, while this differentiation was not significant. However, the assessed changes of DMFT values in the group with orthodontic treatment during six-month observation period were statistically significant. An average DMFT value for the group with orthodontic treatment was 4.35 during the first examination and increased to 4.48 after 6 months of orthodontic therapy. In turn, an increase of DMFT value in the control group from 4.10 to 4.15 was not significant. The assessment of DMFT components demonstrated differentiation between both analyzed groups. $D$ value in the group with orthodontic treatment, as opposed to the control group, decreased significantly after 6 months of observation. At the same time, $F$ value in the group with fixed braces increased statistically significantly during each of three examinations, while in the control group, only slight increase of $F$ value between the first and second examinations was observed. The treatment index of the study group increased from 0.85 (first examination) to 0.93 (third examination), compared to the control group, where its value changed from 0.78 (first examination) to 0.8 (third examination). Statistically significant increase of number of fillings in the group with orthodontic treatment and statistically significant decrease of decayed teeth in this group was probably connected with oral health examinations during monthly orthodontic visits.

Literature review does not clearly indicate the impact of orthodontic treatment on DMFT value. Gupta and Singh [10] observed statistically significant difference in DMFT values between a group with orthodontic treatment and control group. Their study revealed significantly higher frequency of caries occurrence in orthodontic patients. Studies of Hadler-Olsen et al. [11] reported that caries in persons with orthodontic treatment did not statistically differ compared to a control group. An increase in caries occurrence was high only in some patients from the group with orthodontic treatment and control group; however, in the majority, caries did not occur, or its increase was insignificant. Chen and Zhou [12], who compared caries severity between the treated with fixed braces and not treated groups, did not observe any significant difference both before and after the treatment. However, they noted that the treatment with fixed braces decreased the risk of caries development in the group with orthodontic treatment even more than 7 years after finishing the therapy. Baumgartner et al. [13] showed less frequent occurrence of caries on contact surfaces in a group with completed orthodontic treatment compared to control group. Wisth et al. [14] indicated slightly higher DMFT value in a group without orthodontic treatment compared to group with fixed braces. Results of this study showed tendency to less frequent occurrence of caries in a group of orthodontic patients.

In order to protect against caries during an orthodontic therapy, increased hygienic regime is recommended. However, literature review indicates lack of definite consent regarding the impact of the state of oral hygiene on caries. Śmiech-Słomkowska et al. [15] proved that a proper oral hygiene was not sufficient enough to reduce Streptococcus mutans and Lactobacillus bacteria; therefore, orthodontic patients could be endangered with higher risk of caries occurrence. Radlińska et al. [16] underline the fact that even with very high level of cariogenic bacteria in oral cavity, caries does not have to develop, especially with the presence of strong inhibitors, such as calcium, phosphates, and fluorine in saliva and plaque. The authors underline the fact that carious process includes a balance between demineralization and remineralization; therefore, the dependence between oral hygiene and caries should not be directly considered. Orthodontic treatment coincides with a higher level of caries occurrence, which may be one of the reasons why orthodontists are frequently criticized for contribution to an increase of caries intensity [14]. As shown in Zachrisson and Zachrisson study [17] in a part of patients undergoing orthodontic therapy, new carious cavities did not develop, showing that orthodontic treatment does not always have to harmfully influence the teeth. However, there is a group of people with increased risk of caries development; therefore, an increase of DMFT index observed by some researchers in both groups needs to be considered as well as a lack of consent regarding the impact of fixed braces on increase of caries intensity.

\section{CONCLUSIONS}

Orthodontic treatment does not significantly influence an increase of DMFT index in the group of teenagers with orthodontic treatment compared to the control group in the first six-month period of the therapy with fixed appliances. Frequent visits at the dentist office during orthodontic treatment result in an increase of treatment index in patients treated with fixed appliances.

\section{CONFLICT OF INTEREST}

The authors declare no potential conflicts of interest with respect to the research, authorship, and/or publication of this article.

\section{REFERENCES}

1. Enerbäck H, Möller M, Nylén C, et al. Effects of orthodontic treatment and different fluoride regimens on numbers of cariogenic bacteria and caries risk: a randomized controlled trial. Eur J Orthod 2019; 41: 59-66.

2. Øilo M, Bakken V. Biofilm and dental biomaterials. Materials 2015; 8: 2887-2890.

3. Grünheid T, Sudit GN, Larson BE. Debonding and adhesive remnant cleanup: an in vitro comparison of bond quality, adhesive remnant cleanup, and orthodontic acceptance of a flash-free product. Eur J Orthod 2015; 37: 497-502.

4. Bergamo AZN, Matsumoto MAN, Nascimento C, et al. The orthodontic appliances break the salivary homeostasis of microorga- 
nisms involved in dental caries. J Appl Oral Sci 2019; 27: e20180426.

5. Chatterjee R, Kleinberg L. Effect of orthodontic band placement on the chemical composition of human incisor tooth plaque. Arch Oral Biol 1979; 24: 97-100.

6. Maret D, Marchal-Sixou C, Vergnes JN, et al. Effect of fixed orthodontic appliances on salivary microbial parameters at 6 months: a controlled observational study. J Appl Oral Sci 2014; 22: 38-43.

7. Jung WS, Kim H, Cho EJ, et al. Quantitative analysis of changes in salivary mutans streptococci after orthodontic treatment. Am J Orthod Dentofacial Orthop 2014; 145: 603-609.

8. Gaszyńska E, Wierzbicka M, Marczak M, et al. Thirty years of evolution of oral health behaviours and dental caries in urban and rural areas in Poland. Ann Agric Environ Med 2014; 21: 557-561.

9. Rodkowska E, Wilczyńska-Borawska M, Bagińska J, et al. Epidemiological analysis of dental caries in 12-year-old children residing in urban and rural settings in the Podlaskie region of north-eastern Poland. Ann Agric Environ Med 2013; 20: 325-328.

10. Gupta A, Singh K. Assessment of oral health problems in patients receiving orthodontic treatment. Dentistry 2015; 5: 2

11. Hadler-Olsen S, Sandvik K, El-Agroudi MA, et al. The incidence of caries and white spot lesions in orthodontically treated adolescents with a comprehensive caries prophylactic regimen - a prospective study. Eur J Orthod 2012; 34: 633-639.

12. Chen W, Zhou Y. Caries outcomes after orthodontic treatment with fixed appliances: a longitudinal study. Int J Clin Exp Med 2015; 8: 2815-2822.

13. Baumgartner S, Menghini G, Imfeld T. The prevalence of approximal caries in patients after fixed orthodontic treatment and in untreated subjects. J Ortofac Orthop 2013; 74: 64-72.

14. Wisth PJ, Nord A. Caries experience in orthodontically treated individuals. Angle Orthod 1977; 47: 59-64.

15. Śmiech-Słomkowska G, Jabłońska-Zrobek J. The effect of ora health education on dental plaque development and the level of caries-related Streptococcus mutans and Lactobacillus app. Eur J Orthod 2007; 29: 157-160.

16. Radlińska J, Piskorski P, Weyna E, et al. Zachowania zdrowotne i stan zębów dzieci szkolnych. Prz Stomatol Wieku Rozw 1994 6-7: 91-92.

17. Zachrisson BU, Zachrisson S. Caries incidence and orthodontic treatment with fixed appliances. Scand J Dent Res 1971; 79: 183-192. 